\title{
Like Bees to a Flower: Attractiveness, Risk, and Collective Sexual Life in an AIDS Epidemic
}

\author{
Margaret Frye, ${ }^{a}$ Nina Gheihman ${ }^{b}$
}

a) University of Michigan; b) Harvard University

Abstract: We examine how men's shared understandings of women's physical attractiveness are influenced by concerns about risk in the context of a generalized AIDS epidemic. Using 180 conversational journals-descriptions of informal conversations about sex occurring in Malawi between 1999 and 2011-we show that men deploy discourses of risk to question and undermine the status advantages enjoyed by attractive women. Men simultaneously portray attractive women as irresistibly appealing and as destructive to men. Men engage in two types of collective responses: First, men work to discipline themselves and each other, reframing attractiveness as illusory and unworthy of pursuit; and second, men endeavor to discipline attractive women themselves, portraying them as evil temptresses that must be suppressed and reasserting their masculine dominance through harassment and violence. These findings reveal how men's classifications of women as sexual objects operate as forms of symbolic violence, legitimating and naturalizing their gendered domination over women.

Keywords: attractiveness; risk; AIDS; Africa; culture; symbolic violence

\begin{abstract}
"Women are like flowers and men are like bees that land on where there are bright petals, and it is very easy for a bee to be trapped when it lands on a flower." - Conversational journal by Simon Bellos, Malawi, 2003
\end{abstract}

Citation: Frye, Margaret, and Nina Gheihman. 2018. "Like Bees to a Flower: Attractiveness, Risk, and Collective Sexual Life in an AIDS Epidemic." Sociological Science 5: 596-627.

Received: July 23, 2018

Accepted: August 21, 2018

Published: September 26, 2018

Editor(s): Jesper Sørensen, Gabriel Rossman

DOI: $10.15195 /$ v5.a25

Copyright: (C) 2018 The Author(s). This open-access article has been published under a Creative Commons Attribution License, which allows unrestricted use, distribution and reproduction, in any form, as long as the original author and source have been credited. (C) (i)
$\mathrm{T}^{\mathrm{N}}$ the generalized AIDS epidemic in sub-Saharan Africa, sex remains a fundamen1 tal source of pleasure and social connection but is also laced with danger. Here and elsewhere, seemingly throughout history, attractive women are classified by men as simultaneously desirable and threatening (Dworkin 2000; Herdt 2009; Horney 1932). The social science literature relating women's physical appearance to the sexual domain has primarily focused on the social distribution of attractiveness and the benefits that attractive women enjoy compared to less attractive women (Becker 1978; Green 2014; Laumann et al. 1994; Waller 1937; Zetterberg 1966). But the physical attractiveness of women is never solely about individual attributes; assessments of attractiveness are embedded in systems of power and shaped by cultural understandings of both desire and risk. The relationship between power relations and systems of cultural classification is usefully summarized by the concept of the "field," which is increasingly relevant in the study of sexual life (Bourdieu 1996, 2001; Green 2014; Martin and George 2006). This article advances a field-theoretic perspective on men's collective evaluations of attractive women that through its focus on the nexus of attractiveness and risk, accounts for power and patterns of domination. 
Attractive women have been shown to enjoy status advantages across domains. Compared with less attractive women, they experience greater popularity among peers, favorable performance evaluations in school and at work, a higher likelihood of being hired, and improved marital stability (Hosoda, Stone-Romero, and Coats 2003; Jæger 2011; Mulford et al. 1998; Stewart 1980). Attractive women are even thought to be morally superior; outward beauty is unconsciously assumed to signify inward virtue, honesty, and kindness (Tsukiura and Cabeza 2011). As Webster and Driskell (1983:141) write, "The world must be a more pleasant and satisfying place for attractive people because they possess almost all types of social advantages that can be measured."

In the sexual domain, sociological research also treats women's physical attractiveness as a status advantage, a resource that women can "trade" in a dating market or a type of "capital" that improves women's positions in a sexual field (Becker 1978; Farrer 2010; Green 2011, 2014; Laumann et al. 1994; Martin and George 2006; Waller 1937; Zetterberg 1966). This research is premised on the idea that heterosexual men make decisions about potential sexual partners primarily according to whom they most desire. Measured against this benchmark, attractiveness will indeed always be advantageous. Missing from this body of research, however, is a consideration of how perceptions of risk and exercises of symbolic violence enter into men's classifications of women. All sexual encounters involve some degree of risk, including disease, unwanted pregnancy, emotional anguish, and loss of control, and decisions about sex are shaped by anticipated harm as well as pleasure (Muehlenhard and Peterson 2005; Richard, Van der Pligt, and De Vries 1996). At the same time, men's assessments of women are driven by men's collective effort to use symbolic systems of classification-status hierarchies, ranking criteria, and moral judgments - in order to legitimate their masculine power and reassert their dominance in the face of new threats (Bourdieu 1996, 2001; Bourdieu and Wacquant 1992).

We examine heterosexual men's shared understandings of women's attractiveness in a context of heightened sexual risk: southern Malawi between 1999 and 2011. Drawing on a unique data set comprised of conversational journals-descriptions of informal conversations about sex over this 12-year period-we show how men collectively draw upon discourses of risk to question and intentionally undermine the status advantages enjoyed by attractive women. In these debates and discussions, groups of men simultaneously portray attractive women as destructive to men and as irresistibly appealing, and the allure of attractiveness is tainted by the new danger of HIV, which combines with preexisting threats to material vitality and patriarchal power. Men also engage in collective responses, which take two forms. First, men work to discipline themselves and mitigate their own desire, reframing female attractiveness as illusory and unworthy of pursuit; and second, men endeavor to discipline women and restrain the objects of their desire, portraying attractive women as forces of evil that must be suppressed. Both types of responses reveal how men's classifications of women as sexual objects operate as forms of symbolic violence, legitimating and naturalizing their gendered domination over women. 


\section{Theoretical Framework}

\section{Attractiveness and Men's Classification of Women}

Research on sexuality has long invoked the metaphor of the market, in which heterosexual men and women pair off by exchanging skills, attributes, and resources with each other (Becker 1978; Waller 1937; Zetterberg 1966). Whereas men's status in this sexual "marketplace" is thought to reflect their position vis-à-vis other social hierarchies, women's status is believed to be more autonomous. Women are said to "trade" their attractiveness for men's socioeconomic resources and achieve upward mobility through partner selection (Laumann et al. 1994; see also Martin and George 2006).

Recently, scholars studying the social organization of sexuality have advanced the sexual field as a fruitful alternative to the market approach (Farrer 2010; Green 2014; Martin and George 2006). This perspective also considers attractiveness to be a resource through which women secure more desirable partners. Here, attractiveness contributes to erotic capital, or the physical attributes and techniques of self-presentation that elicit erotic responses from others (Green 2008; Hakim 2010). The field-theoretic approach builds on the earlier market perspective by allowing for local and historical specificity in which physical characteristics are prized; erotic capital only makes sense within a given sexual field (Green 2014). Empirical research indeed demonstrates that we appraise each other's appearance differently across contexts and historical conditions (Balogun 2012; Mears 2011). Additionally, whereas the market approach assumes relatively equal exchanges of one set of attributes for another, sexual field theory focuses instead on the relative positioning of people vis-à-vis each other, and thus acknowledges that one person often has more resources or power than the other during sexual and romantic encounters (Green 2008, 2014; Martin and George 2006).

We extend this bourgeoning literature on sexual fields in two directions. First, the prevailing logic of classification in sexual field theory remains rooted in desireproponents of sexual field theory focus primarily on "tiers of desirability" and "structures of desire" (Green 2014) - and fails to incorporate how men evaluate women (particularly attractive women) based on the degree of risk that a sexual encounter might incur (Muehlenhard and Peterson 2005; Richard et al. 1996). Portrayals of attractive women posing a threat to men abound in popular culture. From Ulysses fleeing the Sirens to the femme fatales of Victorian literature, attractive women are routinely represented as seducing and endangering men (Creed 2012; Hedgecock 2008). As Horney (1932:84) writes, "Men have never tired of fashioning expressions for this experience: the violent force by which man feels himself drawn to the woman, and, side by side with his longing, the dread lest through her he might die and be undone." Attractive women are portrayed as posing a threat not only to individual men but also to the social order (Dijkstra 1996) and as such are often singled out as scapegoats (Donald 2010; Dworkin 2000). At times, these fears have burgeoned into full-blown moral panics, resulting in widespread efforts to contain the threat posed by women's sexuality, with the witch hunts of earlymodern Europe serving as the most dramatic example (Cohen 1972; Dworkin 2000; Herdt 2009). 
Psychological research supports the notion that being around attractive women increases men's sense of personal vulnerability (Ariely and Loewenstein 2006; Baker and Maner 2008; Karremans et al. 2009; Wilson and Daly 2004). Attractive women "increase men's awareness of their own corporeality and thus mortality" (Landau et al. 2006:129) and thus place men's social dominance in question: "It is because of intense desire-combined with distinctly human concerns about death-that men sometimes distance themselves from [attractive women] and generally devalue them" (Landau et al. 2006:141). Yet a consideration of the various ways that men perceive-and classify - attractive women as threatening is missing from research on how sexual life is socially organized. Both the market and field approaches assume that sexual interactions and decisions are shaped by desire and by the perceived likelihood of an individual successfully realizing his or her desires. The Malawian case provides an ideal setting for examining how men reconcile the conflicting dimensions of desire and threat as they confront a pervasive risk of death and disease as consequences of sexual attraction.

Second, despite a stated intention to develop "a sociology of collective sexual life" (Green 2014), this body of research has thus far focused on individual actors and romantic dyads. As Adam and Green (2014:126) describe, beyond the dyad, sexual field theory suggests that actors in the sexual field influence each other primarily through indirect means; they "constitute an assemblage of bodies against which one theorizes a sexual status order and one's location within it." Scholars have yet to examine empirically how these "second-order desires" are constructed, refined, and shared among groups of actors. Through examining conversations that occur among groups of men during everyday-life encounters, we focus on the homosocial processes (Flood 2008) that influence heterosexual life: the shared meanings, dialogic styles, and patterns of behavior that emerge within groups of men as they observe and discuss the women around them.

By focusing on collective discussions through which groups of men classify women, rather than dyadic pairings, our analysis incorporates a dimension of Bourdieu's field theory that has been neglected in extent analyses of the sexual field: that of symbolic violence (Bourdieu 1979, 1996). Bourdieu defines symbolic violence as the "power. . . to impose meanings. . . as legitimate by concealing the power relations that are the basis of its force" (Bourdieu 1979:4). Symbolic violence connotes the ability of dominant groups to control schemas of classification such that both the dominant and the dominated perceive those classifications as natural and inevitable. Bourdieu's notion of symbolic capital is centered on the idea that these schemas of classification appear benign despite the fact that they are wielded by the dominant groups to reproduce inequalities of power, influence, and agency: "the transformation of self-interest into disinterest" (Schwartz 1997:90). Bourdieu and Wacquant (1992:170) describe gender domination as the "paradigmatic form of symbolic violence" because the schemas of classification through which men assert their dominance over women are imposed as a "universal viewpoint" that is rooted in nature and biology. And yet, the canonical anthology on sexual fields (Green 2014) contains only passing references to symbolic violence. By focusing on how schemas of classification of women as potential sexual objects-and the systems of power that they uphold-are reinforced through everyday talk by groups of men, 
this article lays bare the role of symbolic culture in producing and reproducing gender domination.

These interventions are connected to one another. An empirical focus on risk is ideal for investigating the collective dynamics of sexual life for three reasons. First, attending to sexual risk highlights the ways that men resist succumbing to their desire, often coaxing each other to do so. This in turn shifts our analytic focus away from the dyadic pairings that do occur and toward the discussions and interactions between men about the potential pairings that should not (or cannot) occur. It is through discussing potential sexual encounters and debating the boundaries that demarcate "good" and "bad" partners that groups articulate the shared schemas of classification that structure the sexual field.

Second, evaluations of risk involve appraisals of women in terms of the stereotypes or social categories that are mapped onto them rather than their unique biographies and individual characteristics, particularly when the women are unfamiliar to the men who evaluate them. These appraisals are canonical forms of what Bourdieu $(1979,1996)$ describes as processes of social classification. Men search for behavioral cues and physical attributes that, in their view, connect a particular woman to a social category and establish her as "that type of woman." As our data will demonstrate, this process of identifying and categorizing visible manifestations of sexual risk is carried out in concert, and the cues and attributes that signal risk are worked out and elaborated upon through interactions between groups of men. By attending to the ways that men collectively debate and discuss the risk involved in a sexual encounter with particular women who are unknown to them, we are able to empirically examine how men appraise, evaluate, and classify women and how these processes contribute to systems of symbolic gender domination.

Finally, among groups of men, sexual risk constitutes a shared problem to solve. Although individuals differ in their available options for sexual partners, all sexually active heterosexual men face the same array of negative consequences of having sex with the "wrong" women. At the same time, attractive women constitute a societal-level threat. As these women both tempt and potentially endanger men, they place men's social dominance in question. By focusing on sexual risk, we are able to examine how men respond to these threats by collectively reconfiguring the meanings of women's attractiveness and by policing the boundaries around acceptable expressions of women's sexuality in public spaces.

\section{Conceptualizing Sexual Risk in Malawi}

Although definitions of risk vary across disciplines, most involve individuals attempting to make connections between current behavior and future consequences under conditions of uncertainty. We conceptualize sexual risk as the perceived potential for a sexual encounter to cause negative repercussions. In our data, most sexual risks fall into three broad categories: biological (HIV infection), material (loss of money), and social positional (loss of power or control). A risk can be salient due to the severity of the negative outcome itself or to the likelihood of this negative outcome occurring (Rogers 1997). In Malawi, HIV risk is perceived as the most severe in terms of its consequences, whereas material and social-positional risks are 
described as more probable. Importantly, our definition of risk is subjective; we do not use this term to connote an actual increased likelihood of negative outcomes occurring but rather to reflect people's perceptions of that likelihood.

Biological risks involve the potential for sex to affect a person's body or physical health, including injury, pregnancy, and disease. For men in rural Malawi, the most potent biological risk associated with sex is HIV infection. The first case of HIV was diagnosed in Malawi in 1985, and the epidemic peaked in 1999 with 16 percent of adults aged 15 to 49 years being infected with the disease (Government of Malawi 2014). The prevalence rate has declined gradually since then and was 11 percent in 2010 (National Statistical Office of Malawi and ICF Macro 2011). ${ }^{1}$

The AIDS epidemic in Malawi cannot be understood through infection rates alone. By 2001, more than 90 percent of adults knew someone who had died of AIDS (Watkins 2004); in 2009, 40 percent of 15- to 25-year-olds had lost a family member to the disease. ${ }^{2}$ Most Malawians' personal relationship to AIDS is best characterized by unremitting uncertainty; they are haunted by what they "know that they don't know" (Trinitapoli and Yeatman 2011:935). This anxiety about current and future infection pervades everyday decisions around when to have children (Trinitapoli and Yeatman 2011), whether to invest in education (Grant 2008), and most poignantly, whom to have sex with (Kaler 2004; Watkins 2004).

Against the backdrop of the epidemic, Malawians continue to live their lives; they start relationships, get married, and have children. Rather than maintaining strict abstinence or condom use, men often attempt to select safer partners through "social diagnoses" (Watkins et al. 2017). Through debates and discussion, men in rural Malawi identify ways of determining a woman's sexual history through her reputation and appearance: signs that she may have had more previous partners or that her partners were riskier (Kaler 2004; Watkins 2004; Watkins et al. 2017). These men's responses to the epidemic are similar to those of gay men in the United States, who often rely on stereotypes or "seroguessing" to choose partners whom they believe to be safer rather than avoiding casual sex or anal intercourse altogether (Zablotska et al. 2009). A meta-analysis of more than 250 studies from around the world suggests that this is a general strategy: "Young people assess the disease risk of a potential partner by how well they know their partner socially, their partner's appearance, or other unreliable indicators" (Marston and King 2006:369).

In the African context, men's social diagnoses of potential sexual partners center on women's perceived attractiveness (Frye and Chae 2017; Kaler 2004; Stadler 2003; Watkins 2004; Watkins et al. 2017); for example, in South Africa, "young 'beautiful women' were said to 'buy their own coffins' [die of AIDS]" (Stadler 2003:128). Recent evidence suggests that this pervasive cultural association between attractiveness and risk of HIV infection is epidemiologically false. Women who were rated by their survey interviewers as attractive were actually less likely than those who were perceived as unattractive to later become infected with the disease (Frye and Chae 2017). Nonetheless, as we show here, the widespread schema linking female attractiveness with HIV risk is culturally salient; it influences how men perceive and respond to attractive women.

Material risks refer to the financial consequences of engaging in sexual relations. Across sub-Saharan Africa, sexual relationships involve a social expectation of 
regular financial transfers from men to women; as Hunter (2002:101) writes, "Sex is simultaneously material and meaningful in complex ways." Because women are typically excluded from the formal labor market, these "transactional relationships" are often vital to women's ability to secure basic needs, such as food and housing (Hunter 2010; Verheijen 2013). With increasing socioeconomic development and emerging markets for consumer goods, however, the gifts that men bestow upon their female partners have shifted in recent decades away from survival and toward consumption to include fashionable clothing, cosmetics, and cell phones (Hunter 2010; Leclerc-Madlala 2003; Mojola 2014; Swidler and Watkins 2007).

The cultural expectation that men provide women with a steady stream of giftsexpressed through the idiom "no romance without finance" across Eastern and Southern Africa-leads men to devote large portions of their income to pursuing women sexually (Hunter 2010; Mills and Ssewakiryanga 2005; Mojola 2014; Swidler and Watkins 2007). Yet despite these efforts, poor men are often unable to start or maintain sexual relationships, and thus, they harbor resentment toward wealthier men who "consume many of the area's women" (Hunter 2010:167). These financial worries influence men's deliberations about potential partners. Men assume that all women will expect some money but search for warning signs that particular women are "money lovers" who will make unreasonable financial demands or leave them for richer men (Poulin 2007). As Mojola (2014:96) describes, these financial concerns are linked to women's appearances: "For young men who wanted to pursue relationships, many chose to avoid girls they perceived as expensive or financially demanding even though they recognized that these expenses were spent on products to make them look beautiful and attractive."

Social-positional risks typically involve a potential loss of power, status, or control through sexual relationships. Here, women's sexuality is understood as posing a threat to systems of hegemonic masculinity (Connell 2005) or patriarchal power (Kandiyoti 1988). Malawian women traditionally held responsibilities extending far beyond the household (Phiri 1988), and during the pre-colonial era, women were "holders of the fields" (Verheijen 2013:24). As in other regions of sub-Saharan Africa (Wyrod 2016), male domination in Malawi is inextricably linked to Western modernization projects. Colonial rule and more contemporary development efforts imposed a male-headed family form and limited access to formal wage labor to men (Hirschmann and Vaughan 1984; Verheijen 2013). These influences have "eroded the material basis for women's relative autonomy without offering attenuating modifications in either marketplace or marital options" (Kandiyoti 1988:277).

In the sexual domain, Malawian men hold considerable power over women. Women and girls are held to strict standards of sexual purity and moral restraint (Ahlberg 1994); only men can "propose" or ask women to have sex or start a relationship (Poulin 2007), and within relationships, women are expected to be subordinate to male sexual desire (Verheijen 2013). Yet, sexuality also represents a threat to male power; as Izugbara and Undie (2008:281) describe, Malawian youth "constitute masculinity as very fragile and in need of constant protection, making the boys wary both of female partners who refuse them sex and of sexual practices which offer little or no control and power over women." The female body is believed to pose a potent challenge to male dominance, and seductive women are 
perceived as dangerous because of men's inability to resist them (Angotti et al. 2014; Watkins and Swidler 2013). And as a result of the AIDS epidemic, practices through which men typically asserted sexual dominance are now perceived as dangerous: "Typical male behaviour. . is implicated in the transmission of HIV; at a deeper level, so is the concept of masculinity that drives this behaviour" (Kaler 2003:367).

\section{Data and Methods}

\section{Data}

The Malawi Journals Project, which began in 1999 and is ongoing, was first designed as a qualitative supplement to a longitudinal household survey (Watkins and Swidler 2009). Frustrated by the limitations of the survey format, the principal investigators hired local participant observers ("journalists") to document conversations related to AIDS that took place around them. If the journalists overheard a conversation concerning AIDS, they were instructed to write down what people said and did within a day of the event occurring. Journalists were paid \$30 (US dollars) for each completed notebook of handwritten observations. Thus far, the project has produced 1,054 80-page notebooks that averaged 7,500 words in length; most are publicly available online. ${ }^{3}$

The journals are an incredibly rich source of information about daily life in rural Malawi, and these texts provide a number of advantages over more conventional sources of data (Watkins and Swidler 2009). They capture people's opinions as expressed organically rather than in a formal interview setting. Because the journalists select the episodes to write about and the details to include, the data reveal which concepts are most salient and which ideas are conjoined in this cultural context. These data are ideal for understanding meaning making as a collective process, as they incorporate the disputes, humor, and contradictions that are inherent to everyday talk but typically are missing from sociological data. The conversational journals have thus far provided insights into various aspects of sexual life in Malawi, including the role of humor in AIDS discourse (Tavory 2014), semiotic meanings surrounding condoms (Tavory and Swidler 2009), gendered schemas of sexuality (Kaler 2003; Schatz 2005), strategies for avoiding HIV infection (Kaler 2004; Watkins 2004), local perceptions of HIV testing and antiretroviral treatment (Conroy, Yeatman, and Dovel 2013), and the contrasting moral understandings of AIDS in newspapers versus everyday life (Angotti et al. 2014).

Because the researchers (intentionally) never specified what was meant by "conversations related to AIDS," the data reflect the journalists' own discretion about what was appropriate to document and often include discussions of sexuality and romantic life more broadly, even when AIDS is not mentioned. As the project's website states, the conversations recorded in the journals pertain to "love, sex, illness, life, death, and more-much more. . . These texts constitute a unique archive not only of the epidemic in Africa but also of everyday life in rural villages at the turn of the millennium." Thus, although these data are particularly germane to our study because of their rich detail about local understandings of AIDS, they 
also provide insight into how other forms of sexual risk are culturally linked to women's attractiveness.

As in any project, the quality of the data depends on those who collect them. Some journalists contributed vivid accounts, whereas others wrote in less detail. With this type of data, fabrication is an important potential concern. We are confident, however, that the journals are genuine recollections of real events for several reasons. First, the same pseudonyms are used throughout, and researchers have successfully triangulated across texts and found descriptions of the same individuals and events by journalists who live in close proximity to each other (Watkins and Swidler 2009). Additionally, the first author lived and worked with many of the journalists over several months in 2008, 2009, and 2011, and during this time, she discussed the process with them at length and personally witnessed them writing accounts of conversations that they overheard or participated in. And finally, as Tavory and Swidler (2009:1745) write, "In the rare cases when diarists 'cheated,' they did so clumsily, often copying pamphlets from local health centers or religious tracts from their churches." These cases were easily removed from the corpus, as these institutional accounts are easily distinguishable from informal conversations through writing style and content.

A total of 24 journalists contributed to the project between 1999 and 2012. The conversational journals are relatively balanced between male and female perspectives: 45 percent of them were written by women. However, the texts include far more examples of men discussing the sexual desirability and appearance of women than women of men, and because interaction is mostly gender segregated in Malawi, our analysis is derived primarily from conversations written by men. Of the 180 journals that constitute our analytic sample (described below), about 10 percent (19) were written by women. When female journalists write about sexual risk, the subject is most often the possibility of contracting HIV from an unfaithful husband or his misuse of household finances. This disparity could be due to the fact that women do not talk about sexual attraction as much as men, to the fact that they do not do so in public places, or to the fact that female journalists did not record these conversations due to gendered standards of sexual propriety. Ethnographic research from Malawi suggests that this is not simply a limitation of our data source; Verheijen (2013:117) writes the following:

Overhearing women discuss amongst each other their contemporary relationship choices suggests that attraction and affection were expressed almost exclusively by adolescent women. Most women. . . reveal a far more pragmatic approach to relationships and try to advise youngsters to make what they consider wiser choices. . . . It seems that throughout life, women are taught [to] value livelihood security over romantic feelings.

Regardless of the reason, we necessarily focus our analysis on heterosexual men's evaluations of women, though we include women's voices when possible.

The journalists are young adults in their 20s or 30s. They live in rural villages, and most lack electricity and running water. All of the journalists hold secondaryschool degrees and are occasionally employed by temporary research projects 
that pass through the areas in which they live, and some secure other short-term contracts with nongovernmental organizations (NGOs) or health facilities. But for most of the period documented in the journals, they survive as farmers and experience the restlessness and discontentment common to the "interstitial elite" across rural Africa: young adults who are educated enough to feel unsatisfied with subsistence farming but who lack the credentials needed to secure stable employment (Swidler and Watkins 2009). Their conversation partners vary from close friends or relatives to strangers met in passing, most of whom live nearby and work as farmers or own small businesses, such as shoe repairing or driving a bicycle taxi. In short, the voices documented in the journals are those of poor but not destitute individuals in the midst of normal life in rural Malawi.

The unit of analysis in this article is a "conversational incident," an exchange between two or more people that is bounded by time and space (Angotti et al. 2014). Participants may arrive or leave, and the topic may change, but the incident ends when all participants leave or the journalist stops recounting. The sample of 1,054 journals yielded 4,080 conversational incidents.

\section{Analytic Sample}

With a corpus of 4,080 texts, our first task was to select a subsample of conversational incidents to analyze for this project. Our sampling strategy is based on a case study logic rather than the representative sampling logic that is typically used in quantitative research (Small 2009). If our primary goal was to determine whether (or how often) specific individuals consider sexual risk when evaluating potential partners, we would require a random sample of all conversations about potential sexual partners that occurred in public spaces. If this were our objective, the corpus we use would not be appropriate because the conversations documented in the journals were preselected by the journalists to involve discussions of sexual risk. Instead, we sought to document the social processes through which risk perceptions influence shared understandings of and responses to women's attractiveness. Thus, we used dictionary-based computational text analysis to identify an analytic sample of the 180 incidents that were most likely to be relevant to our study, incidents in which discussions of attractiveness (identified through the dictionaries) and risk (a basic inclusion criterion for the corpus) overlap to a significant degree.

Dictionary approaches begin with a list of words or phrases that are related to a concept or topic of interest and generate counts of how often each term appears in each text in the corpus as well overall scores that aggregate across all words included in the dictionary. We relied on two different dictionaries to select our sample. The first dictionary includes words related to attractiveness. We began with a random sample of 488 conversational incidents that had previously been summarized for another project (Angotti et al. 2014) and used these summaries to identify 81 incidents that were particularly relevant for the current questions. We both read all incidents in this preliminary sample and constructed a list of 36 terms that were frequently used to describe whether or not women were considered to be attractive (Table 1). These correspond to four categories: body parts, fashion or clothing, verbs, and adjectives. The second dictionary identifies incidents in which women 
Table 1: Words included in the attractiveness dictionary.

\begin{tabular}{lcc}
\hline Word Type & Words Included & Average Number Included in Sample \\
\hline Body parts & $\begin{array}{c}\text { Hair, hips, legs, buttocks, butt, thigh, } \\
\text { shoulder, back, arms, waist, stomach }\end{array}$ & 1.6 \\
Clothing & $\begin{array}{c}\text { Naked, pants, fashion, tight, style, skirt, dress, } \\
\text { miniskirt, clothes, clothing, blouse, cosmetics }\end{array}$ & 7.4 \\
Verbs & $\begin{array}{c}\text { Tempt, attract, wear, seduce } \\
\text { Adjectives }\end{array}$ & $\begin{array}{c}\text { Beautiful, handsome, sexy, young, pretty, } \\
\text { smart, fat, plump, seductive, bare }\end{array}$ \\
\hline
\end{tabular}

are observed in a casual setting. Our preliminary analysis revealed that these incidents typically occur in the market or on the road and involve a description of a woman passing by the conversation participants. We thus constructed a dictionary composed of the terms "pass by," "walk by," and "walk past" (including all tenses). By juxtaposing the terms related to attractiveness with those related to women passing by, we were able to identify texts that were topically relevant and also to capitalize on a real strength of our data: their potential to capture discussions sparked by everyday social encounters.

We used this dictionary to rank all incidents in the full corpus, first by the number of unique terms from the appearance dictionary and then by the number of "pass by" phrases. In order to ensure that our sample is distributed across the 12 years of data, we split the data into three time periods and selected the 60 entries with the highest rankings for each period (180 total).

Computational text analysis was used to identify the cases that were most likely to be relevant for our study, but the analysis itself is based on detailed qualitative coding of all texts in this analytic sample. This sampling method allowed us to identify a more salient and informative set of texts than a random sample would have provided; however, it is no substitute for a close reading of the texts.

\section{Analysis and Coding Scheme}

We performed the qualitative analysis using the software platform Dedoose. We constructed an initial coding scheme by reading all cases in our preliminary sample and met regularly to discuss and refine these codes throughout the study. We used codes to identify excerpts related to the following: (1) people's appearance, (2) behaviors that were described as increasing or decreasing an individual's sexual desirability (e.g., dancing and staying out late), (3) the character of either a specific woman or women in particular (e.g., women as irresistible and women as always being after money), (4) perceived sexual risks, and (5) strategies to mitigate risk during sexual encounters.

We also assessed each incident according to men's evaluations of women along two dimensions: attractiveness (more versus less attractive than average) and HIV risk (more versus less risky than average). For each of these measures, we also included a category for incidents when both opinions were expressed (suggesting 
debate or disagreement) and a "not applicable" ("NA") category. Finally, we created memos for each incident, which include a detailed summary of the events and discussion that took place, reflections on how the case confirms or contrasts with other cases in our sample, and new ideas that occurred to us while coding the case.

\section{Findings}

\section{How Men Classify Women as Attractive in Rural Malawi}

Our data provide many examples of men "checking women out" during everyday life: on the street, in the market, and at the bus stop. Of the 180 cases in our analytic sample, 132 include evaluations of the attractiveness of specific women encountered by men in public places (see Table 2 for a summary of the prevalence of this and other analytic themes). The following passage provides a typical example of how men discuss the appearance of a woman walking by, in this case, at the market:

As we were resting, a beautiful young dancer passed by where we stood. She was of medium height, not really fat, with breasts that stood firm; her twinkling eyes were amazing, she had a well-curved body that would have been a hit on any catwalk, and above all, she was dressed to kill. She wore a tight miniskirt, a fishtail blouse that ended above her navel, and she was brown in complexion. [My friend said] "Wow! What a beautiful creature. Look!" He pointed at her. "Look the way she walks, look at her beauty, look [at] her buttocks shaking as if she is doing a fashion show, look [at] her breast, very portable in hands. Oh!" [Magwira, September 6, 2005]

Men's remarks about women's appearance typically involve descriptions of erotic body parts (buttocks, legs, and breasts), physique (praise for being "plump" or "fat"), complexion ("brown" or "light" skin and use of cosmetics), and fashionable or sexy clothing. These markers of attractiveness often overlap with those signifying class. Women are more easily able to achieve a plump figure if they have access to steady food and are only able to afford cosmetics, hair treatments, and fashionable clothing if they have excess financial resources. In some cases, men describe money as changing a woman's level of attractiveness, as in the following excerpt:

He went on saying, "For example, I may see a single woman having children to support alone, and she doesn't look beautiful and good because soap and body chemicals are very rare to her, and the end result is that she lives very miserably and is dull in appearance. . . . after someone gives her enough capital and she is running a big business and has enough to care for herself, she can have pretty clothes and then you may find that a lot of men begin going after her because she is now pretty." [Simon, August 19, 2003]

Women's appearance sometimes signals cultural categories that are also class coded, including "town girls" (in contrast to "village girls") and "schoolgirls." 
Table 2: Prevalence of major themes discussed in the article.

\begin{tabular}{|c|c|c|}
\hline Description of Codes & $\begin{array}{l}\text { Number of Incidents } \\
\text { Containing Code }\end{array}$ & Percent $^{1}$ \\
\hline \multicolumn{3}{|l|}{ Evaluations of Attractiveness and Risk } \\
\hline Incidents in which women were evaluated in terms of their attractiveness & 132 & $73 \%{ }^{2}$ \\
\hline Incidents in which women are described as more attractive than average & 111 & $84 \%$ \\
\hline \multicolumn{3}{|l|}{ Incidents involving a positive association between: } \\
\hline Attractiveness and HIV risk & 94 & $71 \%$ \\
\hline Attractiveness and financial risk & 36 & $27 \%$ \\
\hline Attractiveness and loss of power and/or control & 65 & $49 \%$ \\
\hline \multicolumn{3}{|l|}{ Reasons Why Attractiveness Is Considered Risky } \\
\hline Other men also pursue attractive women & 21 & $16 \%$ \\
\hline Attractive women are intentionally seductive & 69 & $52 \%$ \\
\hline Men are weak and unable to control their desire in the presence of attractive women & 62 & $47 \%$ \\
\hline \multicolumn{3}{|l|}{ Men Disciplining Men: Reframing Attractiveness As Unworthy of Pursuit } \\
\hline Attractiveness as a material commodity & 29 & $22 \%$ \\
\hline Women are "all the same" & 35 & $27 \%$ \\
\hline \multicolumn{3}{|l|}{ Men Discipling Women: Attempts to Restrain the Objects of Desire } \\
\hline \multicolumn{3}{|l|}{ Framing attractive women as a social danger that must be contained } \\
\hline Attractive women as tools of Satan & 31 & $23 \%$ \\
\hline Attractive women as inviting rape & 22 & $17 \%$ \\
\hline \multicolumn{3}{|l|}{ Incidents of verbal or physical violence toward attractive women } \\
\hline Incidents of verbal abuse: mocking and shaming attractive women & 20 & $15 \%$ \\
\hline Incidents of physical abuse: beating attractive women or stripping them of clothing & 6 & $5 \%$ \\
\hline
\end{tabular}

Clothing that is considered the norm in urban centers is often sexualized in rural Malawi, where women typically tie long chitenge cloths around them as skirts. Pants in particular are considered seductive because they accentuate a woman's legs rather than hiding their shape and because they are symbolic of Western influence. The following excerpt demonstrates that men believe women from towns are more attractive than the "plain" women they encounter in villages:

You know in town that there are more beautiful girls, and whenever they come dressed up, every man admires them. . . indeed, there are more beautiful girls in each and every town, and even though girls here in the village are proud, it would be a great shame indeed if they had seen how beautiful their fellow friends are in towns. [Simon, September $15,2004]$

Schoolgirls are also generally considered to be attractive, and are easily spotted, because they wear uniforms and keep their hair short. These visible manifestations of attending school are indicators of class, as most girls who remain in school through later adolescence come from well-to-do families. Moreover, while at school, young women learn to use lotions, makeup, and other products that allow them to present themselves as "modern" (Mojola 2014). In the journals, schoolgirls are praised by men for these techniques of hygiene and self-presentation. As one man says, "A lot of men flock to them because of their cleanliness and the belief they have that schoolgirls are sweet [sexually pleasurable]" [Simon, August 19, 2003].

Although biological attributes matter as well, both what is defined as attractive and the extent to which individuals can effectively alter their physical appearance 
are shaped by people's social positioning (Balogun 2012; Mears 2011). Although it does not guarantee attractiveness, class background is an important determinant of men's appraisals and commentary about women's appearance, similar to what has been documented in other contexts (Duneier and Molotch 1999). As we shall demonstrate, these dynamics of status are important to consider when analyzing how attractiveness overlaps with sexual risk and the processes through which men seek to reassert power over attractive women.

\section{The Association of Attractiveness and Risk}

Attractive women passing by spark not only attraction but also trepidation, and these incidents often involve discussions of risk as well as desire. Of the three types of sexual risk that we examine, discussions of AIDS most frequently co-occur with evaluations of attractiveness in our data (Table 2). ${ }^{5}$ Attractiveness and HIV risk are positively associated in more than 70 percent of the 132 cases involving discussions of specific women: 87 cases describe women being evaluated as both attractive and likely to have HIV, and 7 describe unattractive women as less likely to have HIV. In contrast, there are only 10 cases in which women are evaluated as both attractive and less likely to have HIV. ${ }^{6}$ In these 10 outlying cases, men explain why they think specific attractive women are safer, typically citing their modest demeanor or the fact that they are young and "unsullied." The fact that men usually provide justifications for why they believe that an attractive woman is safe provides further evidence that attractiveness and risk are culturally linked.

Two examples illustrate how men's classifications of attractiveness and appraisals of HIV risk overlap with one another. In the first, seven men are playing bawo, a popular board game, when two women pass by, and the discussion shifts from sexual attraction to AIDS:

There passed two women who were dressed in modern fashion clothes. .. and one man among the men who were there said we are not going to survive from getting AIDS because of women wearing such clothes. "Just see how these women are dressed, if they come at you. . . in a seductive manner, won't you fall into their behavior? You can obviously fall head down!" Then another guy named Michael said, "You don't mind AIDS when you see such beautiful girls." [Diston, August 13, 2002]

In the second, the journalist Simon is eating breakfast when an attractive young woman walks by, spurring reactions from a group of men nearby:

While I sat at a certain mini-shop [café] taking my breakfast, a certain plump girl black in complexion was moving along the road. When she was proudly passing by, everyone glanced at her, and I heard a few young men whistling and mocking her movements. I heard one say, "We will all die because of these girls." [Simon, December 3, 2003]

These excerpts reveal how men's conversations about other topics turn to fatalism and hopelessness about AIDS when a sexy or attractive woman walks by. In both 
excerpts, we also see how class and status differences underlie evaluations of attractiveness. In the first, the women are wearing "modern fashion clothes," and in the second, the woman is described as walking "proudly."

Attractive women are also described as posing financial risk; such evaluations co-occur in 36 cases in our data (Table 2). Men warn each other that if they pursue attractive women, they will be stripped of their financial resources, as these women desire material goods to further embellish their appearance:

Then he warned me that "it's better to be careful with these beautiful women since they are after money and not real love, and when you don't have money, your sexual partner can't love you." He continued saying that "love of today is that of the pocket, and if you are pocketless [poor], there is no love, and such women cannot accept you." [Simon, December 28, 2003]

In another example, men describe the merits of pursuing poor, less attractive women, who are less likely to go after the man's money:

And he said, "I encourage you men not to go for a woman because of her beauty but go for a poor woman who can persevere in any economic situation. And such women can be found only in rural areas, not in urban ones, because the urban women are used to fashion which always needs more money, and once you fail to buy what they demand, then you are in trouble with them, until you have nothing." [Diston, June 25, 2002]

These passages show that men depict attractive women as harboring destructive intentions that threaten not only their health but also their economic viability, as these women seek to deprive men of their money.

Men describe attractive women as placing them at risk of losing power and control in 65 unique conversations (Table 2). Attractive women are portrayed as "hijacking" men and forcing them to bend to their will, as in the following example: "Then he went on saying that. . . when wanting to marry one should look, apart from a faithful girl, one should make sure that he marries not a beautiful one because then you cannot be hijacked by anyone" [Simon, February 24, 2003]. Men portray women as causing them to be literally overcome by desire and unable to make rational decisions:

Whenever a girl or a woman displays her legs, the thighs well groomed and in good condition, a faithful man forgets to reason and loses his senses." [Simon, July 12, 2003]

My friend smiled and said, "... The women are so very, very beautiful that you can't even think. . . They seduce you to the maximum, so that you even come to forget your country Malawi." [Simon, June 13, 2002]

Together, our data show that the classification schemas of attractiveness and risk overlap, naturalizing the castigation and vilification of attractive women. Women 
are sorted into oppositional categories-attractive, powerful, and dangerous versus unattractive, powerless, and safe. Rendering these categories essential to the women themselves and linking them to the women's (assumed) behavior, these classification schemas allow men to symbolically legitimate their own dominant positions-and to put attractive women in their place.

\section{Naturalizing the Threat of Attractive Women}

Men cite three primary reasons why attractive women pose sexual risks: women's popularity, women's seductiveness, and men's weakness. Regarding women's popularity, men use the fact that they imagine and witness other men pursuing attractive women to justify the assumption that they must have had more sexual partners. More sexual partners, in turn, means more chances to contract HIV compared to "unbeautiful" or "plain" women. Discussions of attractive women having numerous suitors and sexual partners occurred in 21 incidents; the following excerpts show two typical cases:

Then Mr. Khongwa said, "That's the problem with beautiful women: They are at a high risk of getting infected with AIDS because more men get attracted to beautiful women than those who are not beautiful." [Diston, July 22, 2010]

[My friend] said, "The other things killing us men with AIDS is that we normally want to marry or have sexual relationships with someone who looks very beautiful indeed and not unbeautiful. . . forgetting that these beautiful ones go with many sexual partners because they are beautiful, and a lot of men who have a lot of money go to them." [Simon July 14, 2003]

In addition to the biological threat of HIV, attractive women's popularity with other men also invokes the threat of competition over money. In one example, several men stand around a chips stand at the market advising each other to avoid marrying beautiful women, and the chips seller says, "Make sure you take someone not beautiful to avoid competing with other men who propose [to] someone's wife because they have money" [Simon, July 14, 2003].

Regarding seductiveness, men do not view women as passive actors whose attractiveness is beyond their control. They believe women to be complicit in this process, intentionally using their looks to lure men into danger:

Mr. Mudyeso added that, "There are some women that just show you their thighs and you can't [resist] them, the seductiveness persists and pressures your mind, you wish to sleep with her right then and there." [Simon, May 21, 2002]

And Nhamo continued, "Women are not people to play with because they have more ways of overcoming you." [Diston, September 10, 2003]

The younger boys followed her, singing. . . "There she walks, her buttocks shaking, attractive with the intention to kill many." [Briford, July 26, 2005] 
Attractive women are described as intentionally seducing men in 69 separate incidents (Table 2). Although most of these cases involve women being described as luring men into placing themselves at risk of contracting HIV, in one case, a woman is described as using her looks to seduce a man and move up the social ladder: "You may find a beautiful young lady dressed to kill going to an interview while she knows that she doesn't qualify for the job. She only wants to use her body as a qualification, and since we humans are made of weak bones. . . the woman is employed, who is to be blamed?" [Magwira, January 9, 2006].

Regarding weakness, men consider themselves, both personally and collectively, to be defenseless before women they desire. Men's inability to suppress their sexual appetites around attractive women is mentioned in 62 unique incidents (Table 2). The men characterize their sexual desire as a blinding frenzy that renders them weak and incapable of making sound choices:

My friend Shadie said, “I believe a man can't resist a woman's seduction by her beauty. That is why I tell you, man, there is no way to end AIDS. ... I couldn't resist her attraction." [Simon, September 1, 1999]

Then the third guy among them said, "There are some beautiful women whom after they have accepted to have sex with you, you forget that there is either AIDS or condom use because of their beauty so that you just go for them regardless of what may come later on." [Diston, December 27, 2003]

I agreed with him, and he said that indeed we men we are like mad dogs, we go by looks alone and not love at all; even knowing that the girl is moving with another sexual partner, you find that the man still goes after her only because of her looks. ... He said that's why a lot of men are catching AIDS nowadays. [Simon, August 20, 2003]

Even men who are supposed to know better, such as highly educated professors and policy makers, are believed to be hypocrites, powerless and "stupid" before attractive women:

Then [the man at the bar] said that, "You see even very educated professors and doctors at the university dying of HIV / AIDS because if they see such hips, they end up having unprotected sex. They are the ones writing books, they are policy makers for HIV / AIDS, but even though they advise people, they do wrong things behind [the public's eyes]." [Haji, December 31, 2006]

The man who was speaking said, "It is very sad to hear that even now, there are some men who pretend to be clever, yet they are stupid in the hands of a woman." [Simon, May 21, 2002]

Even as they are irresistibly drawn to attractive women, men portray these women as essentially and inevitably threatening to their economic vitality, to their positions of dominance relative to women, and to their very lives. Through references to the women's past behavior, their illicit motivations, and the perverse power they wield over all men, these statements naturalize their classifications of 
the women as threatening. In the sections that follow, we describe two ways that men respond to this perceived threat. First, on an individual level, men seek to reduce one another's desire for attractive women and enhance their resistance to the temptations such women pose. Second, on a collective level, men aim to suppress the object of desire by shaming and mocking attractive women and reasserting male domination.

\section{Men Disciplining Men: The Collective Reaffirmation of Schemas of Classification}

The classification of attractive women as naturally threatening is not made in passing. The journals often reveal men repeatedly invoking these schemas in the same conversation, offering support to one another in their efforts to resist their desire for attractive women and recasting attractiveness itself as unworthy of desire. Typically, these passages begin when one man confesses that he is tempted by a woman whom he knows personally or whom he sees passing in the village, and those around him advise him on the importance of avoiding her and protecting his life, such as in the following example:

There were five men [standing by the road]. After some minutes, a certain young woman was passing by. She. . . had plump buttocks that were wriggling [and] shaking vigorously as she was walking on the tarmac road heading towards Balaka bus depot. When she had just passed by, one of them said, "But indeed, she is a real lady, look at her." His friends all glanced towards her, escorting her with their eyes. . . . One said, "Following that, we are not going to be spared in this world." ... One man said that such kinds of ladies are dangerous because many people, even rich men, compete with each other over winning her. . . . Another said ,"Nowadays if you want a lady, it's better to have sex with a lady who is not good looking because men are not concerned with her, hence you can't get AIDS." [Simon, October 4, 2009]

This process extends beyond friends, as strangers advise each other on the merits of resisting beauty. In one case, the journalist and a friend visit a nightclub and meet two attractive women. When the women go to dance, a stranger comes over to warn them that these women likely have HIV. The journalist and his friend nickname this stranger "Good Samaritan" because they find his advice useful. The journalist writes, "This Good Samaritan said that we should stay away from the two girls. He said, 'You should not be cheated with big buttocks, or you will die"' [Philimon, January 15, 2006].

When cautioning each other about the danger of attractive women, men frequently employ the trope "not all that glitters is gold" to signify that these women may not be all that they appear. In another example of a stranger offering advice, a bus driver who witnessed a passenger talking to an attractive woman warns him that she may have HIV given how she is dressed: "He said to me that I should be careful since not all that glitters is gold" [Simon, August 13, 2003].

During these discussions, men not only offer advice about ways to suppress desire; they also redefine attractiveness itself as artificial, illusory, and unworthy of 
attention. Men collectively reframe attractiveness in two ways. First, they describe attractiveness as a material commodity that can be purchased through fashion and cosmetics rather than as an embodied attribute of the women themselves. Second, they try to convince themselves-and each other-that women are "all the same" and that their experience of sex will not differ according to whether their partners are attractive. We describe each attempt to reframe attractiveness in turn.

When trying to convince each other that attractive women do not merit the strong desire they feel for them, men often define attractiveness as artificial, a product of material consumption. This idea is expressed in 29 separate conversations (Table 2). Men argue that because clothing, makeup, and lotions create it, attractiveness is not inherent to women. Therefore, there is no benefit to pursuing attractive women because their appeal could be put on or taken off by anyone. In one example, the journalist and his brother join a group of men at the market in discussing what makes a woman appealing. One man says, "But because we men are blind, we. . . get attracted to their looks, their artificial hips, face, hair, and the like without knowing that they are killing us with selfish desire" [Magwira, January 9, 2006]. In another example, the journalist is on a bicycle taxi, and the driver describes how men should check themselves when they feel desire toward a woman because this desire is rooted in the money she spent on her appearance:

He continued saying that he is a human being and subjected to. . . temptations, and that if he happens to admire a lady, first of all, he asks himself what made him admire her, then he comes to an answer that it's because she dresses well or made up her hair and has enough money to buy the dress or. . . to go to the salon. [Simon, April 7, 2011]

Men extend this argument by advising each other that because attractiveness is created through clothes and makeup, they should simply buy these items for their own wives:

[The restaurant owner] said, "When you have seen some beautiful woman, try to find out what makes you admire that particular woman. . . . At last you can conclude that it's only dressing that makes her beautiful and the cosmetics that she applies on her body. So then try to buy these for your wife, and if you try that, you may see that she will be looking beautiful and others will be admiring her. And these days, when you see a skirt on the body of the girl and you want to undress her by sleeping with her, just know that you may have no more days in this world in these days of AIDS diseases." [Simon, December 3, 2003]

The men recognize that access to material goods improves women's attractiveness, and they reject this class dimension as illegitimate. They describe women who spent money on their appearance as selfish, greedy, and as "cheaters" who buy beauty. These passages show these men's resentment not only of the women they find themselves drawn to against their will but also of these women's ability to leave behind the class they were born into via consumption. By redefining all beauty as illusory and artificially constructed, they seem to reject their own feelings of desire and deny any biological basis for the attraction they feel. 
Men also redefine attractiveness as unworthy by claiming that the experience of sex is the same with any woman, so a partner's beauty will not enhance a man's sexual experience. Women are described as "all the same," with their attractiveness being declared irrelevant to sexual pleasure, in 35 separate conversations in our data (Table 2). The men advise each other that the stronger desire they feel for attractive women is a construction of their minds rather than being rooted in reality:

He went on saying that he was the kind of man who had slept with many women and girls in this world, and he had come to conclude that women are all are the same. [Another man agreed that] women are not different, but it is only our mentality that makes us think that women are different in terms of sweetness [pleasurable sexual feeling]. [Simon, September 14, 2003]

One man at the bawo playing place who is named Mr. Haston looked at her and said, "That woman is fat and beautiful and she has got nice buttocks, but the only thing that I know is that women are the same regardless of their body structure." [Diston September 20, 2010]

Men invoke this idea of the fundamental similarity of women when counseling each other to remain faithful to their wives because sex with them is no worse than with the women they are attracted to in public. On his way home, Simon stops by a maize mill to visit two friends, and they discuss this issue:

And Stefano said, "We married men, it's better if we only trust our wives, for women are the same but Satan or the devil makes us see women as different, but they aren't; even if we bring all the women and make them take off their skirts and dresses, you may see that they are the same, so why are we troubled, we men looking for other sex partners while we have ours at home, are we trying to provoke AIDS? It's better to be satisfied with whatever we have at home." [Simon, June $13,2001]$

These excerpts show that men respond to the threat posed by attractive women through advising each other about the dangers that attractive women pose and by redefining beauty as unworthy of desire. These strategies center around the uncontrollable desire that the men feel, and thus focus primarily on the risks that attractive women pose to men on an individual level. Yet, these strategies also constitute a collective process of classification, with men reaffirming together the group hierarchies of the sexual field. In the next section, we present an alternative response to the threat of attractive women: disciplining women for the threat they pose to men. It is here that the gendered power dynamics that undergird sexual life come to the fore, and these strategies address the ways that attractive women challenge men's collective domination.

\section{Men Disciplining Women: Strategies to Reassert Masculine Dominance}

Even as they work to strengthen their own resistance, men also blame the women who tempt them: They describe attractive women as hostile temptresses intending 
to harm men and strip them of their power. In these passages, such women are demonized as tools of Satan and described as inviting rape and sexual violence. These aggressive orientations extend beyond the level of discourse as men humiliate and abuse attractive women in public spaces. The perceptions of danger and attributions of blame embedded in men's seemingly innocuous conversations about the women around them thus inform a range of behaviors, from sidewalk catcalls to outright violence.

Women, and particularly attractive women, are consistently described as using magic and charms to lure men, often with references to the devil:

He continued saying, "The way these girls dress nowadays it's so attractive that a man cannot resist proposing [to them]. Satan works so supernaturally in trying to bring people to his side, wanting to put them in trouble." [Simon, May 29, 2004]

I heard the teacher saying, "... Men are in great danger now that there are more beautiful girls indeed, and Satan's influence leads us to follow him to the unquenchable fire in [hell]." [Simon, August 17, 2005]

And he said, "Satan is trying in every way to groom women to be looking beautiful and attractive so that when a man sees her, he loses self-control." [Simon, December 3, 2003]

Attractive women are described using references to Satan in 31 incidents (Table 2). These references are reminiscent of how women have been characterized as using enchantment to ensnare men throughout history (Creed 2012). By connecting attractive women with evil, Malawian men reveal the fear and defenselessness that female sexuality incites within them. At the same time, these passages suggest that attractive women are to blame for the mortal threat that their physical presence poses.

Descriptions of attractive women often involve references to rape or other forms of sexual violence. Men describe women who dress seductively or look attractive as "inviting rape" 22 times in our data, as in the following passages:

My friend Chilito said, "If I met her alone walking in the street, I would go and rape her. The way she is dressed, it seems somehow seductive, inviting to be raped. . . . You can even take a razor blade and just cut. . . between her buttocks, because the trousers she put on are so tight, and just insert the member [penis]." [Simon, September 1, 1999]

The people in the minibus laughed, and C. continued, "What I can tell you also is that if women are frequently being raped nowadays, it's because of the way they are dressing. [Women are] taking a big role in spreading AIDS by making men to have sex." [Thomas, August 4, 2005]

These cases show men policing the boundary of how alluring women can appear in public. When women dress in tight or revealing clothing, these choices are described as ample justification for rape. By describing women who dress seductively as "spreading" AIDS and "inviting" rape, men condone the most aggressive reactions to the dangers posed by attractive women. These statements portray attractive 
women as societal threats that must be controlled and policed even through recourse to violence.

These attitudes are not confined to abstract discussions. They also seep into everyday encounters in which attractive women become targets of public humiliation. Our analytic sample contains 20 instances in which attractive women are subjected to verbal or physical abuse in public spaces (Table 2). We offer three specific examples of groups of men engaging directly with attractive women, working together to suppress these women's seductive allure and reassert their own domination. In two cases, the women defend themselves, suggesting that attractive women are not passive victims in these struggles even if their protests are ignored or silenced by those who torment them.

In the first example, as a woman walks through the market, young men begin shouting at her, borrowing lyrics from a popular song mocking beautiful women:

The young lady took much interest of the young men, people automatically changed their topic of discussions and started talking of her, mainly of her beauty and of what people suggested that she does. There was a shout and whistles all over, some appreciating her beauty and others insulting her, but she kept silent and started to walk forward. There were a lot of insults calling her a whore, a killer, [and] a walking corpse [and] connecting her [appearance] to a certain song by Soul Chembezi that is full of advice about beauty. The song says those who are beautiful outside, inside them there is poison. And since the young lady had everything in the song, young men didn't hesitate to call her a walking corpse, a whore, but she didn't respond. [Magwira, April 9, 2006]

As the men invoke the rhetoric of risk and move from flirting to harassment, they seem to use this specific woman as an opportunity to express a general fear of the danger posed by attractive women. In this case, the men highlight the woman's own mortality as a tactic to underplay their own.

In the second example, a female journalist recounts a scene involving men running after a group of girls and forcibly removing their clothing:

Some young ladies at Mwendo were walking in the street while wearing blouses with short skirts that were also tight so that when walking, their bodies were shaking, especially the buttocks. . and when they were passing the market, men were laughing and shouting at them, but the shouts and laughter did not disturb them. They were just walking, but a certain young man ran after them and tore the skirt off one of them and ran away. The young women began to shout at the young man; they used obscene language. The girls were saying that the young man is so stupid and doesn't know how people dress in new fashions, that's why he has done such a stupid thing. . . . But people were still laughing and shouting at the girls, telling them to leave the place and put on more clothes. [Patuma, August 1, 2004]

Despite the women talking back to their perpetrators and asserting their more cosmopolitan identity, the collective nature of the men's response suggests a general 
societal attitude that women deserve harsh treatment for stepping beyond the socially prescribed standards of self-presentation. The men move beyond mocking to physical harassment, humiliating the women in front of a laughing crowd.

The third episode, the most dramatic and disturbing of the three, takes place on a public minibus, a common form of transportation in rural Malawi. In these vehicles, men and women are crowded together into confined spaces, and tensions bubble up and occasionally spill over. We again witness the scene through a woman's eyes. The incident begins when an attractive woman boards a bus:

She sat on a back chair. . . . Then men who sat on a back seat started to shout at her. . . . Her blouse was showing half of her back. Her shoulders were outside [bare]. Men continued by saying that, "If she can be raped, will she claim that men have raped her?" because this means that she is seducing herself to men. [Anna, March 30, 2005]

As in the previous example, the woman tries to defend herself against these threats by reframing her clothing choices as symbolic of her higher-class status relative to the men, though she is ultimately unsuccessful: "The girl said to the men that they don't know how life is. They came from villages that are far away from the town. ... Then the men told her to be silent." The account then takes a darker turn when a man begins to undress the woman in front of the passengers:

One man said that people must leave him so that he can have sex with her in the minibus while people were there. . . . But the girl started to beat him. People in the minibus started also to beat her. The time when she was quarrelling with the men, the women were just keeping quiet, and we all looked down with shyness. But some women also were beating her. So, the driver stopped, and a crowd of people came to see what was happening. And then they removed all her clothes, and she remained naked. We left her there while she was crying. [Anna, March 30, 2005]

These episodes demonstrate how men seek to discipline attractive women for "displaying themselves." The last example is particularly poignant not only because it reveals both verbal mocking and physical harassment but also because of the response of the onlookers. It is striking to observe how supportive the passengersboth male and female-seem to be of the central man's aggression. This scene thus reveals physical violence as well as symbolic violence: The woman is perceived by the public as deserving of her fate, and her denigration appears inevitable and legitimate. Attractive women are culturally classified as inherently dangerous and deserving of social humiliation and moral policing. When walking around in public, these women therefore attract not only men's desirous attention but also their castigation and violence.

\section{Discussion and Conclusions}

Our analysis has revealed a cultural intersection between the meanings attached to physical attractiveness and those related to sexual risk. Men both desire and 
dread beautiful women. Our unique data source captures how men in public spaces construct these meanings and classify women through routine, everyday talk. This research highlights the collective nature of sexuality, as groups of men respond to the perceived threats posed by attractive women in two ways. First, they attempt to mitigate their own desires through reaffirming the schemas of classification and collectively reframing beauty as artificial and undesirable. Second, they reassert power over the objects of their desire-the women themselves-through public mocking, rape discourse, and in extreme cases, physical violence.

These findings provide two important interventions into meso-level theories of how collective meanings structure sexual life. First, we demonstrate the importance of considering risk in frameworks of deliberation and evaluation. Sexual fields, just as other social fields, are composed of organized systems of relations (Farrer 2010; Green 2008, 2014; Martin and George 2006). As in a magnetic field, forces of attraction and opposition create social positions by orienting people toward or away from each other (Martin 2003). Analyses of sexual fields have thus far focused mainly on the forces of attraction, examining how cultural schemas, institutional structures, and broader systems of inequality influence which attributes and characteristics are considered desirable. But developing a theory of the "social organization of desire" (Green 2008) is not enough to understand how sexual life is structured because sexuality is shaped by risk and domination as well as by desire and pursuit. In contrast, epidemiological analyses of sexual life in Malawi and elsewhere in Africa have focused on vectors of risk, estimating the likelihood that a particular sexual encounter will result in infection and underemphasizing the importance of desire in shaping sexual interactions. We have sought to contribute a more holistic approach, understanding how these two sets of vectors-the pull of desire and the push of risk-together influence men's collective classifications of women's attractiveness and their efforts to legitimate their gendered dominance.

Second, we move field analysis beyond dyadic pairings, demonstrating empirically that cultural meanings about sexuality are constructed and refined within groups. Although field theory offers a conceptual apparatus for examining relations between groups or categories of individuals, we know of no empirical analyses of these dynamics in the sexual realm. By focusing on conceptions of sexual risk, we highlight the collective elements of sexual life that are invisible in studies of dyadic configurations. Studying risk helps us to see how groups of men together position themselves relative to categories of women: attractive versus plain, seductive versus shy, and good versus evil. At the same time, by focusing on processes of symbolic violence and the legitimation of structures of power, we incorporate group-level domination - a fundamental component of Bourdieu's field theory-into field-theoretic perspectives of collective sexual life.

The analysis also contributes to cultural sociology more broadly, as the emphasis on groups rather than dyads shows empirically how cultural meanings are worked out at a collective level. As the men bond over desiring something that could potentially harm them, our data reveal these fears bubbling up into the collective consciousness and motivating communal responses. We show that men work together to reshape their own experience of desire in part to lessen the power that attractive women hold over them, whether real or perceived. The men also act 
collectively to define and reinforce boundaries of acceptable behavior for attractive women and exercise coordinated punishment when women step outside these boundaries. Through these collective processes, in turn, the classification of attractive women as threatening begins to appear natural and preordained, an essential characterization of these women and an inevitable corollary of the hazardous times they live in.

By connecting men's evaluations of specific women to broader structural and cultural dynamics present in Malawi-the AIDS epidemic, precarious economic circumstances, and a male-dominant cultural system-we provide a case study of how micro-level constructions map onto macro-level inequalities. Two axes of inequality that are particularly prominent in our data are class and gender inequalities. Often, what makes a woman attractive is her use of consumer goods, such as cosmetics, hair treatments, and fashionable clothing, that lend her a modern, cosmopolitan appearance. Men regard women who "buy" beauty as "cheating" to gain unfair leverage over their biological predispositions and attach nefarious intentions to these efforts. By castigating these women for their attractiveness, or for the perceived misuse of their attractiveness, these men negate the women's material advantages and reassert their own dominant status.

Gender inequality is also expressed in multifaceted ways in our data. Despite Malawi's record of women holding positions of power-some tribal chiefs are women, and Joyce Banda served as president (the second female head of state in Africa) from 2012 to 2014- on the ground, the cultural frameworks and institutions reaffirm the domination of women. These misogynistic cultural frameworks and male-dominant institutional configurations are present across all three types of sexual risks that we analyzed. Attractive women pose a biological risk not only because heterosexual men contract HIV from women but also because of the misogynistic belief that women intend to harm and kill men through sex. They pose a material risk precisely because they are excluded from the wage economy, and so rely on men to provide financial support (Verheijen 2013). Although men giving women money is a customary part of romantic relationships in Malawi, men often use this fact as evidence of women exploiting men for financial gain. Attractive women pose a risk to male power and control chiefly because their sexual allure is one of the few resources available to them to influence men. By describing attractive women as "overpowering" and "hijacking" them, the men take little responsibility for their own sexual appetites and articulate an understanding of male sexuality that excuses their behavior.

There remain some limitations to our data and analytic approach. First, because all of the data were collected during the AIDS epidemic, we are unable to trace the historical trajectory of how attractiveness came to be associated with sexual risk. The most likely scenario is that the AIDS epidemic provides a contemporary symbolic repertoire that men draw upon to enact longstanding rituals of shaming and denigrating attractive women. As described earlier, this is certainly not the first setting in which attractive women have been perceived as a threat and been subject to backlash. However, it is also possible that the unprecedented nature of the epidemic fundamentally transformed the set of meanings that men attach to attractiveness, from a prized attribute to a sign of danger and risk, and that other 
sites of gender-based conflict (money and power) were drawn upon to reinforce these negative connotations. With no data that predate the epidemic and with HIV prevalence changing only slightly during the decade that our data span, we are unable to adjudicate between these two possible scenarios.

Second, we are unable to examine whether men act on their stated claims that they will pursue or avoid a particular woman or whether they are successful if they do pursue her. It is likely that the conversations described in the journals are colored by bravado and selective representations of actual experiences, as are all discussions about sexuality. However, as Martin notes (2014:182), if we wish to understand the broader social configuration of sexual life, it may be more fruitful to look at sexual judgments than rather than decision-making: "The crucial cognitive relation of the actor to [the objects surrounding her or him] is not choice but judgment-the ability to perceive (or 'intuit') the qualities of these objects." By focusing on the systems of meaning that men collectively drew upon to evaluate and classify women, we gain a crucial understanding of how attractiveness and risk intersect and inform each other independent of whether people's behaviors are consistent with these evaluations.

Finally, women's perspectives are largely missing from the accounts that we document. As described above, when discussions of potential partners do occur among women in the journals, they usually involve assessments of these partners' likelihood of being unfaithful or having financial troubles rather than evaluations of their attractiveness or desirability (see also Verheijen 2013). Future research should compare how understandings of risk and desire are collectively constructed by men versus by women and explore possible gender differences in how homosocial processes structure sexual life.

Although the findings we report are specific to contemporary Malawi, we learn lessons that can be extended to other settings. We know that men classifying women as sexual objects, the substantive focus of our analysis, is a global phenomenon. Yet research on the topic has been limited by the nature of the data available. Most work on the topic focuses on women's experiences of sexual harassment collected through retrospective interviews (however, see Khan et al. 2018). To our knowledge, there is only one academic study that analyzes how public sexual harassment happens on the ground (Duneier and Molotch 1999), and ours is the first to examine how groups of men assess and respond to the women they encounter in public places. More broadly, although the content of these public exchanges may be specific to Malawi, sexual risks are part of sexual relations in any society. Research from college campuses in the United States shows that groups of men and women police the fine line between acceptable and detestable sexual behavior (Armstrong et al. 2014; Hamilton and Armstrong 2009; Khan et al. 2018), and it is likely that similar sorts of deliberations and discussions around sexual risks happen in these settings. Although the specific risks may differ-perhaps discussions of social reputation, pregnancy, and other types of sexually transmitted infections (STIs) are more prevalent in the West-analogous interactional processes are likely at play in the groups attempting to navigate them. By examining how these interactions unfold, we witness how cultural meanings are brought to bear on everyday life encounters 
and how these encounters in turn contribute to shared cultural orientations with tangible consequences for the most intimate corners of people's lives.

\section{Notes}

1 Women in Malawi are currently infected with HIV at higher rates and younger ages (National Statistical Office of Malawi and ICF Macro 2011), though the lifetime probability of infection is about equal for men and women.

2 These data come a longitudinal survey called Tsogolo La Thanzi (TLT). TLT is designed by Jenny Trinitapoli and Sara Yeatman and funded by a grant (R01-HD058366) from the Eunice Kennedy Shriver National Institute of Child Health and Human Development. Those interested in obtaining TLT data files should visit https://tsogololathanzi.uchicago.edu/.

3 The Malawi Journals Project can be found at http://deepblue.lib.umich.edu/handle/ 2027.42/113269.

4 All excerpts are referenced using the journalist's pseudonym and the date of the journal; these two attributes are part of the file names in the publicly available data set. Text from the journals was edited to correct grammar and spelling errors, and information has been added in brackets to improve clarity and provide necessary context.

5 Of course, this is due at least in part to the parameters of the data set. As described above, journalists were asked to document conversations pertaining to AIDS, and the data were collected as part of a longitudinal survey investigating the social repercussions of Malawi's AIDS epidemic. Our data are therefore not appropriate to examine the salience of the three types of perceived risk discussed here (AIDS infection, loss of material resources, and loss of power) relative to one another. Instead, we provide counts to establish the evidence base upon which our analysis rests for each of these three types of perceived risk.

6 Fourteen cases describe debate over the women's HIV status, with both opinions expressed, and 14 don't include discussions of the women's HIV status.

\section{References}

Adam, Barry D., and Adam Isaiah Green. 2014. "Circuits and the Social Organization of Sexual Fields." Pp. 123-42 in Sexual Fields: Toward a Sociology of Collective Sexual Life. Chicago, IL: University of Chicago.

Ahlberg, Beth Maina. 1994. "Is There a Distinct African Sexuality? A Critical Response to Caldwell." Africa 64:220-42. https://doi.org/10.2307/1160981.

Angotti, Nicole, Margaret Frye, Amy Kaler, Michelle Poulin, Susan Cotts Watkins, and Sara Yeatman. 2014. "Popular Moralities and Institutional Rationalities in Malawi's Struggle Against AIDS." Population and Development Review 40:447-73. https://doi. $\mathrm{org} / 10.1111 / \mathrm{j} .1728-4457.2014 .00693 . \mathrm{x}$.

Ariely, Dan, and George Loewenstein. 2006. "The Heat of the Moment: The Effect of Sexual Arousal on Sexual Decision Making." Journal of Behavioral Decision Making 19:87-98. https://doi.org/10.1002/bdm. 501.

Armstrong, Elizabeth A., Laura T. Hamilton, Elizabeth M. Armstrong, and J. Lotus Seeley. 2014. "'Good Girls': Gender, Social Class, and Slut Discourse on Campus." Social Psychology Quarterly 77:100-22. https://doi .org/10.1177/0190272514521220. 
Baker, Michael D., and Jon K. Maner. 2008. "Risk-Taking as a Situationally Sensitive Male Mating Strategy." Evolution and Human Behavior 29:391-5. https://doi .org/10.1016/j . evolhumbehav.2008.06.001.

Balogun, Oluwakemi M. 2012. "Cultural and Cosmopolitan: Idealized Femininity and Embodied Nationalism in Nigerian Beauty Pageants." Gender and Society 26:357-81. https://doi .org/10.1177/0891243212438958.

Becker, Gary S. 1978. The Economic Approach to Human Behavior. Chicago, IL: University of Chicago Press.

Bourdieu, Pierre. 1979. "Symbolic Power." Critique of Anthropology, 4:77-85. https ://doi . org/10.1177/0308275X7900401307.

Bourdieu, Pierre. 1996. The Rules of Art: Genesis and Structure of the Literary Field. Palo Alto, CA: Stanford University Press.

Bourdieu, Pierre. 2001. Masculine Domination. Palo Alto, CA: Stanford University Press.

Bourdieu, Pierre, and Loïc Wacquant. 1992. An Invitation to Reflexive Sociology. Chicago, IL: The University of Chicago Press.

Cohen, Stanley. 1972. Folk Devils and Moral Panics. Abingdon, UK: Taylor \& Francis.

Connell, Raewyn W. 2005. Masculinities. Berkeley, CA: University of California Press.

Conroy, Amy, Sara Yeatman, and Kathryn Dovel. 2013. “The Social Construction of AIDS during a Time of Evolving Access to Antiretroviral Therapy in Rural Malawi." Culture, Health and Sexuality 15:924-37. https://doi.org/10.1080/13691058.2013.791057.

Creed, Barbara. 2012. The Monstrous-Feminine: Film, Feminism, Psychoanalysis. Abingdon, UK: Routledge. https://doi.org/10.4324/9780203820513.

Dijkstra, Bram. 1996. Evil Sisters: The Threat of Female Sexuality and the Cult of Manhood. New York, NY: Alfred A. Knopf.

Donald, Stephanie Hemelryk. 2010. "Tang Wei: Sex, the City and the Scapegoat in Lust, Caution." Theory, Culture and Society 27:46-68. https://doi.org/10.1177/ 0263276410372238.

Duneier, Mitchell, and Harvey Molotch. 1999. "Talking City Trouble: Interactional Vandalism, Social Inequality, and the 'Urban Interaction Problem."' American Journal of Sociology 104:1263-95. https://doi.org/10.1086/210175.

Dworkin, Andrea. 2000. Scapegoat: The Jews, Israel, and Women's Liberation. New York, NY: Free Press.

Farrer, James. 2010. “A Foreign Adventurer's Paradise? Interracial Sexuality and Alien Sexual Capital in Reform Era Shanghai." Sexualities 13:69-95. https://doi.org/10. $1177 / 1363460709352726$

Flood, Michael. 2008. "Men, Sex, and Homosociality: How Bonds between Men Shape Their Sexual Relations with Women." Men and Masculinities 10:339-59. https://doi .org/10. $1177 / 1097184$ X06287761.

Frye, Margaret, and Sophia Chae. 2017. "Perceived Physical Attractiveness and Women's HIV Risk in Rural Malawi." Demographic Research, 37:251-94. https://doi.org/10. 4054/DemRes. 2017.37.10.

Government of Malawi. 2014. Malawi Progress Report for 2013. Lilongwe, Malawi: Joint United Nations Programme on HIV/AIDS.

Grant, Monica J. 2008. “Children's School Participation and HIV/AIDS in Rural Malawi: The Role of Parental Knowledge and Perceptions." Demographic Research 19:1603-34. https://doi.org/10.4054/DemRes.2008.19.45. 
Green, Adam Isaiah. 2008. "The Social Organization of Desire: The Sexual Fields Approach." Sociological Theory 26:25-50. https://doi .org/10.1111/j.1467-9558.2008.00317 .x.

Green, Adam Isaiah. 2011. "Playing the (Sexual) Field: The Interactional Basis of Systems of Sexual Stratification." Social Psychology Quarterly 74:244-66. https://doi .org/10.1177/ 0190272511416606.

Green, Adam Isaiah, ed. 2014. Sexual Fields: Toward a Sociology of Collective Sexual Life. Chicago, IL: University of Chicago Press.

Hakim, Catherine. 2010. "Erotic Capital." European Sociological Review 26:499-518. https://doi.org/10.1093/esr/jcq014. https ://doi.org/10.1093/esr/jcq014.

Hamilton, Laura, and Elizabeth A. Armstrong. 2009. “Gendered Sexuality in Young Adulthood: Double Binds and Flawed Options." Gender and Society 23:589-616. https: //doi.org/10.1177/0891243209345829.

Hedgecock, Jennifer. 2008. The Femme Fatale in Victorian Literature the Danger and the Sexual Threat. Amherst, NY: Cambria Press.

Herdt, Gilbert H. 2009. Moral Panics, Sex Panics: Fear and the Fight over Sexual Rights. New York, NY: New York University Press.

Hirschmann, David, and Megan Vaughan. 1984. Women Farmers of Malawi: Food Production in the Zomba District. Berkeley, CA: University of California Intl \&.

Horney, Karen. 1932. “The Dread of Woman." Psychoanalysis and Male Sexuality 13:83-96.

Hosoda, Megumi, Eugene F. Stone-Romero, and Gwen Coats. 2003. "The Effects of Physical Attractiveness on Job-Related Outcomes: A Meta-analysis of Experimental Studies." Personnel Psychology 56:431-62. https://doi.org/10.1111/j.1744-6570.2003.tb00157. $\mathrm{x}$.

Hunter, Mark. 2002. "The Materiality of Everyday Sex: Thinking Beyond 'Prostitution."' African Studies 61:99-120. https://doi.org/10.1080/00020180220140091.

Hunter, Mark. 2010. Love in the Time of AIDS: Inequality, Gender, and Rights in South Africa. Bloomington, IN: Indiana University Press.

Izugbara, Chimaraoke O., and Chi-Chi Undie. 2008. "Masculinity Scripts and the Sexual Vulnerability of Male Youth in Malawi." International Journal of Sexual Health 20:281-94. https://doi.org/10.1080/19317610802412043.

Jæger, Mads Meier. 2011. “'A Thing of Beauty Is a Joy Forever'? Returns to Physical Attractiveness over the Life Course." Social Forces 89:983-1003. https://doi .org/10. 1353 /sof . 2011.0016.

Kaler, Amy. 2003. "My Girlfriends Could Fill a Yanu-Yanu Bus." Demographic Research Special 1:349-72. https://doi.org/10.4054/DemRes.2003.S1.11.

Kaler, Amy. 2004. "AIDS-Talk in Everyday Life: The Presence of HIV/AIDS in Men's Informal Conversation in Southern Malawi." Social Science and Medicine 59:285-97. https : //doi.org/10.1016/j.socscimed.2003.10.023.

Kandiyoti, Deniz. 1988. "Bargaining with Patriarchy." Gender and Society 2:274-90. https : //doi.org/10.1177/089124388002003004.

Karremans, Johan C., Thijs Verwijmeren, Tila M. Pronk, and Meyke Reitsma. 2009. “Interacting with Women Can Impair Men's Cognitive Functioning." Journal of Experimental Social Psychology 45:1041-4. https: //doi .org/10.1016/j. jesp. 2009.05.004.

Khan, Shamus R., Jennifer S. Hirsch, Alexander Wambold, and Claude A. Mellins. 2018. "'I Didn't Want to Be "That Girl"': The Social Risks of Labeling, Telling, and Reporting Sexual Assault." Sociological Science 5:432-60. https://doi .org/10.15195/v5.a19. 
Landau, Mark J., Jeff Greenberg, Sheldon Solomon, Andy Martens, Jamie L. Goldberg, Omri Gillath, Cathy Cox, and Tom Pyszczynski. 2006. "The Siren's Call: Terror Management and the Threat of Men's Sexual Attraction to Women." Journal of Personality and Social Psychology 90:129-46. https://doi .org/10.1037/0022-3514.90.1.129.

Laumann, Edward O., John H. Gagnon, Robert T. Michael, and Stuart Michaels. 1994. The Social Organization of Sexuality: Sexual Practices in the United States. Chicago, IL: University of Chicago Press.

Leclerc-Madlala, Suzanne. 2003. "Transactional Sex and the Pursuit of Modernity." Social Dynamics 29:213-33. https://doi.org/10.1080/02533950308628681.

Marston, Cicely, and Eleanor King. 2006. "Factors That Shape Young People's Sexual Behaviour: A Systematic Review." The Lancet 368:1581-6. https://doi .org/10.1016/ S0140-6736 (06)69662-1.

Martin, John Levi. 2003. “What Is Field Theory?" American Journal of Sociology 109:1-49. https://doi.org/10.1086/375201.

Martin, John Levi. 2014. "The Crucial Place of Sexual Judgment for Field Theoretic Inquiries." Pp. 171-88 in Sexual Fields: Toward a Sociology of Collective Sexual Life. Chicago, IL: University of Chicago Press.

Martin, John Levi, and Matt George. 2006. “Theories of Sexual Stratification: Toward an Analytics of the Sexual Field and a Theory of Sexual Capital." Sociological Theory 24:107-32. https://doi.org/10.1111/j.0735-2751.2006.00284.x.

Mears, Ashley. 2011. Pricing Beauty: The Making of a Fashion Model. Berkeley, CA: University of California Press.

Mills, David, and Richard Ssewakiryanga. 2005. “'No Romance Without Finance': Commodities, Masculinities and Relationships Amongst Kampalan Students." Pp. 90-95 in Readings in Gender in Africa, edited by A. Cornwell. Melton, UK: James Currey.

Mojola, Sanyu A. 2014. Love, Money, and HIV: Becoming a Modern African Woman in the Age of AIDS. Berkeley, CA: University of California Press. https ://doi .org/10.1525/ california/9780520280939.001.0001.

Muehlenhard, Charlene L., and Zoë D. Peterson. 2005. “Wanting and Not Wanting Sex: The Missing Discourse of Ambivalence." Feminism and Psychology 15:15-20. https: //doi.org/10.1177/0959353505049698.

Mulford, Matthew, John Orbell, Catherine Shatto, and Jean Stockard. 1998. "Physical Attractiveness, Opportunity, and Success in Everyday Exchange." American Journal of Sociology 103:1565-92. https://doi.org/10.1086/231401.

National Statistical Office of Malawi, and ICF Macro. 2011. Malawi Demographic and Health Survey 2010. Calverton, MD: ORC Macro.

Phiri, Kings M. 1988. "Pre-Colonial States of Central Malawi: Towards a Reconstruction of Their History." The Society of Malawi Journal 41:1-29.

Poulin, Michelle. 2007. "Sex, Money, and Premarital Partnerships in Southern Malawi." Social Science and Medicine 65:2383-93. https://doi .org/10.1016/j . socscimed. 2007. 05.030 .

Richard, Rene, Joop Van der Pligt, and Nanne De Vries. 1996. "Anticipated Regret and Time Perspective: Changing Sexual Risk-Taking Behavior." Journal of Behavioral Decision Making 9:185-99. https : //doi .org/10.1002/(SICI) 1099-0771 (199609) 9:3<185: : AID-BDM228>3.0.CO;2-5.

Rogers, George O. 1997. “The Dynamics of Risk Perception: How Does Perceived Risk Respond to Risk Events?" Risk Analysis 17:745-57. https://doi.org/10.1111/j. 1539-6924.1997.tb01280.x. 
Schatz, Enid. 2005. “'Take Your Mat and Go!': Rural Malawian Women's Strategies in the HIV/AIDS Era." Culture, Health and Sexuality 7:479-92. https://doi.org/10.1080/ 13691050500151255.

Schwartz, David. 1997. Culture and Power: The Sociology of Pierre Bourdieu. Chicago, IL: University of Chicago Press.

Small, Mario Luis. 2009. "'How Many Cases Do I Need?' On Science and the Logic of Case Selection in Field-Based Research." Ethnography 10:5-38. https://doi.org/10.1177/ 1466138108099586.

Stadler, Jonathan James. 2003. "The Young, the Rich, and the Beautiful: Secrecy, Suspicion and Discourses of AIDS in the South African Lowveld." African Journal of AIDS Research 2:127-39. https://doi .org/10.2989/16085906.2003.9626567.

Stewart, John E. 1980. "Defendant's Attractiveness As a Factor in the Outcome of Criminal Trials: An Observational Study." Journal of Applied Social Psychology 10:348-61. https : //doi.org/10.1111/j.1559-1816.1980.tb00715.x.

Swidler, Ann, and Susan C. Watkins. 2007. “Ties of Dependence: Aids and Transactional Sex in Rural Malawi." Studies in Family Planning 38:147-62. https://doi .org/10.1111/j . 1728-4465.2007.00127.x.

Swidler, Ann, and Susan C. Watkins. 2009. “'Teach a Man to Fish': The Sustainability Doctrine and Its Social Consequences." World Development 37:1182-96. https://doi. org/10.1016/j . worlddev. 2008.11.002.

Tavory, Iddo. 2014. "The Situations of Culture: Humor and the Limits of Measurability." Theory and Society 43:275-89. https : //doi .org/10.1007/s11186-014-9222-7.

Tavory, Iddo, and Ann Swidler. 2009. “Condom Semiotics: Meaning and Condom Use in Rural Malawi." American Sociological Review 74:171-89. https://doi .org/10.1177/ 000312240907400201.

Trinitapoli, Jenny, and Sara Yeatman. 2011. “Uncertainty and Fertility in a Generalized AIDS Epidemic." American Sociological Review 76:935-54. https://doi .org/10.1177/ 0003122411427672.

Tsukiura, Takashi, and Roberto Cabeza. 2011. "Shared Brain Activity for Aesthetic and Moral Judgments: Implications for the Beauty-Is-Good Stereotype." Social Cognitive and Affective Neuroscience 6:138-48. https://doi.org/10.1093/scan/nsq025.

Verheijen, Janneke Pieternel Elisabeth. 2013. Balancing Men, Morals and Money: Women's Agency Between HIV and Security in a Malawi Village. Leiden, Netherlands: African Studies Centre.

Waller, Willard. 1937. "The Rating and Dating Complex." American Sociological Review 2:727-34. https://doi.org/10.2307/2083825.

Watkins, Susan C. 2004. "Navigating the AIDS Epidemic in Rural Malawi." Population and Development Review 30:673-705. https://doi .org/10.1111/j.1728-4457.2004.00037. $\mathrm{x}$.

Watkins, Susan C., and Ann Swidler. 2009. "Hearsay Ethnography: Conversational Journals As a Method for Studying Culture in Action." Poetics 37:162-84. https ://doi . org/10 . $1016 / j$. poetic. 2009.03 .002 .

Watkins, Susan C., and Ann Swidler. 2013. "Working Misunderstandings: Donors, Brokers, and Villagers in Africa's AIDS Industry." Population and Development Review 38:197-218. https://doi.org/10.1111/j.1728-4457.2013.00560.x.

Watkins, Susan C., Gigi Santow, Michel Bracher, and Crystal Biruk. 2017. "Epistemology and Epidemiology: Diagnosing AIDS in Rural Malawi." University of California, Los Angeles California Center for Population Research Population Working Paper CCPR-068-07. 
Webster, Murray, Jr., and James E. Driskell, Jr. 1983. "Beauty As Status." American Journal of Sociology 89:140-65. https://doi.org/10.1086/227836.

Wilson, Margo, and Martin Daly. 2004. “Do Pretty Women Inspire Men to Discount the Future?" Proceedings of the Royal Society of London B: Biological Sciences 271:S177-9. https: //doi.org/10.1098/rsbl.2003.0134.

Wyrod, Robert. 2016. AIDS and Masculinity in the African City: Privilege, Inequality, and Modern Manhood. Berkeley, CA: University of California Press. https://doi.org/10. 1525/california/9780520286689.001.0001.

Zablotska, Iryna B., John Imrie, Garrett P. Prestage, June Crawford, Patrick Rawstorne, Andrew E. Grulich, Fengyi Jin, and Susan Kippax. 2009. “Gay Men's Current Practice of HIV Seroconcordant Unprotected Anal Intercourse: Serosorting or Seroguessing?" AIDS Care 21:501-10. https: //doi .org/10.1080/09540120802270292.

Zetterberg, Hans L. 1966. "The Secret Ranking." Journal of Marriage and Family 28:134-42. https://doi.org/10.2307/349268.

Acknowledgments: We are grateful to Asad L. Asad, Bart Bonikowski, Larissa Buchholz, Caitlin Daniels, Paul DiMaggio, Mitchell Dunier, Pablo Gastón, Michele Lamont, YaWen Lei, Omar Lizardo, Terence McDonnell, Orlando Patterson, Ann Swidler, Lorne Tepperman, and Jocelyn Viterna for their feedback and suggestions for revision. Previous versions of this were presented at Notre Dame's Sociology Departmental Colloquium and African Studies Workshop, Princeton University's Notestein Seminar Series (through the Office of Population Research), Harvard University's Culture and Social Analysis Workshop, the Sociology of Development Conference at Brown University, and the Eastern Sociological Society Annual Meeting.

Margaret Frye: Department of Sociology, University of Michigan.

E-mail: mtfrye@umich.edu.

Nina Gheihman: Department of Sociology, Harvard University.

E-mail: nina.gheihman@fas.harvard.edu. 